\title{
A Tragédia Grega como Recurso Didático
}

\author{
The Greek Tragedy as a Teaching Resource
}

\author{
Tiago Irigary de Bem \\ Graduado na Universidade Federal do Rio Grande do Sul, Porto Alegre, Rio Grande do Sul, Brasil. \\ tiagoirigaray739@gmail.com \\ ORCID: https://orcid.org/0000-0003-4784-3382
}

Recebido em 28 de fevereiro de 2019

Aprovado em 19 de setembro de 2019

Publicado em 07 de janeiro de 2020

RESUMO: Trata-se aqui dos desdobramentos de utilizar a tragédia como recurso didático em aulas de Filosofia do Ensino Médio, o que foi feito no meu estágio curricular obrigatório. O conflito trágico, a ambientação com aspectos da cultura grega clássica, a conexão que a tragédia faz com outros conteúdos filosóficos, o enorme potencial didático das tragédias, bem como a recepção dos estudantes. Defendo que, com o devido alerta sobre anacronismos, os paralelos que podem ser traçados entre a tragédia e os nossos dias se tornam deveras didáticos e possuem, inclusive, grande potencial interdisciplinar.

Palavras-chave: Tragédia; Didática; Ensino de Filosofia; Grécia Clássica; Antígona.

ABSTRACT: I deal here with the consequences of using tragedy as a didactic resource in Philosophy classes in High School, which was done in my obligatory curricular internship. The tragic conflict, the setting with aspects of the classical Greek culture, the connection that the tragedy makes with other philosophical contents, the enormous didactic potential of the tragedies, as well as the reception of the students. I argue that, with due warning about anachronisms, the parallels that can be traced between tragedy and our days become truly didactic and even have great interdisciplinary potential.

Keywords: Tragedy; Didactics; Teaching Philosophy; Classical Greece; Antigone.

\section{Introdução}

Tradicionalmente, as formas de abordagem principais do ensino de Filosofia no Ensino Médio são a partir da História da Filosofia ou a partir de temáticas, questionamentos e problemas filosóficos que podem ser muito variados (ROCHA, 2008). Durante o estágio obrigatório para a disciplina de Estágio de Docência em Filosofia II (cursada no primeiro semestre letivo de 2018, entre março e julho, sob a supervisão do professor Rafael da Silva Cortes) diante de alunos que teriam o primeiro contato com a disciplina de Filosofia $\left(1^{\circ}\right.$ 
ano do Ensino Médio do Colégio de Aplicação da UFRGS), optei pelo viés da História da Filosofia. No entanto, ao invés de iniciar como de praxe, a partir de Platão, o início se deu num momento da sociedade grega antiga que era anterior aos textos platônicos, analisando os elementos da cultura grega que propiciaram o surgimento da atividade filosófica. Visei tratar esses elementos como fazendo parte de uma espécie de "pré-história" da filosofia.

Vários elementos confluem para que a filosofia tenha se originado na Hélade, dentre eles, a tragédia se destaca. Na tragédia grega é possível ver claramente a concomitância entre a linguagem metafórica, o mito, o rito (muthos) e a linguagem conceitual, racional, matemática, científica (logos) (ROSENFIELD, 2014). Ora, a filosofia nasceu a partir da linguagem do logos e, portanto, o plano era demonstrar aos estudantes, a partir do estudo da tragédia, as condições que propiciaram o nascimento da filosofia. Além disso, de acordo com Aristóteles, a tragédia é uma imitação (mimesis), uma poesia imitativa que imita não só uma ação, como também casos que suscitam o terror e a piedade (ARISTÓTELES, 1984). Essa forma de imitação também é caracterizada por retratar os seres humanos como sendo melhores do que eles realmente são (ARISTÓTELES, 1984). Destarte, planejei ler com eles uma tragédia, levantar os pontos filosóficos que havia ali e, só então, partir para a Filosofia propriamente dita - que se desvencilha do muthos - a partir da Estética, através das discussões de Platão (no livro X da República) e de Aristóteles (na Poética, momento em que o conceito de tragédia de Aristóteles seria plenamente trabalhado, embora, infelizmente, $\mathrm{O}$ tempo do estágio tenha sido concluído antes de poder abordar esta obra). Uma vez que a turma se familiarizasse com as questões estéticas, o professor que seguisse tal plano de ensino poderia optar entre duas alternativas de continuidade do conteúdo: prosseguir para as demais teorias de Platão e/ou Aristóteles ou continuar no curso do desenvolvimento da Estética.

Ao longo do estágio, no entanto, ficou claro que o uso da tragédia na sala de aula, um texto geralmente restrito a contextos específicos e eruditos, apresentava qualidades didáticas para muito além do esperado. Neste artigo, apresento as reflexões, resultados, questionamentos e conjecturas sobre o uso da tragédia grega em sala de aula.

\section{A escolha da tragédia}

Das trinta e uma tragédias que chegaram inteiras até nós (sete de Ésquilo, sete de Sófocles e dezessete de Eurípedes), muitas se destacam por apresentarem questões filosóficas em seu enredo. A trilogia da Oresteia (Agamêmnon, Coéforas e Eumênides), de Ésquilo, versa sobre as formas de justiça e suas problemáticas; o Prometeu Acorrentado, de mesmo autor, brinda os leitores e os espectadores com pungentes questionamentos sobre o poder e a violência; Filoctetes, de Sófocles, traz à luz considerações éticas, questões sobre a verdade, as relações de poder e demonstra um verdadeiro exemplo de dialética; $A s$ Troianas, de Eurípedes, destaca-se pela excelente e consistente argumentação da rainha Hécuba ante a perda, o luto e a dor. Há muitas opções de tragédias a escolher que são interessantes recursos ilustrativos e didáticos para muitos mais assuntos além daqueles 
compreendidos no estágio. É bastante útil que os professores de Filosofia tenham consciência disso, uma vez que enriquece a aula e o repertório do professor. As criações dos três tragediógrafos podem ser também excelentes "territórios" para exercer a interdisciplinaridade. Analogamente aos professores de Filosofia, professores de outros componentes curriculares como Literatura, Língua Portuguesa, História, entre outros, podem encontrar um poderoso recurso no gênero trágico, campo fértil para a didática, embora praticamente esquecido pelos docentes e relegado a âmbitos acadêmicos deveras específicos.

Escolher uma tragédia não é tarefa simples, especialmente porque, dependendo do desdobramento filosófico que se pretende abordar, uma tragédia se mostra mais adequada que a outra. É possível, como já dito, partir da tragédia diretamente para os rumos da Estética. Outrossim, pode-se enveredar pelos caminhos da Lógica, da Ética, entre outros a partir dos conflitos da tragédia escolhida. Outros componentes curriculares do Ensino Médio (EM), como História, Português, etc, também encontram terreno fértil nela. $\mathrm{Na}$ Filosofia, a tragédia funciona muito bem como um exemplo "padrão", como um ponto de partida que prossegue para outras questões filosóficas, que sempre podem lançar mão da tragédia como referência e exemplo. É possível iniciar um módulo de Estética a partir de uma tragédia - que foi o executado no estágio - tendo o texto como obra de arte referencial. Analogamente, através da Lógica se encaixa uma abordagem na qual As Troianas e/ou Filoctetes teriam sido uma boa escolha, porque uma excelente argumentação ocorre entre Filoctetes e Neoptólemo e entre Hécuba, Helena e Menelau. O potencial didático desse gênero literário parece ser largamente ignorado nas práticas didáticas voltadas ao EM.

Como a turma teria o primeiro contato (Introdução à Filosofia), era importante que se pudesse traçar paralelos com a realidade atual, e esse foi um dos principais critérios para a escolha. Muitos alunos consideram a Filosofia como uma atividade muito distante da realidade concreta e prática, como foi aferido em experiências prévias como bolsista do Programa Institucional de Bolsas de Iniciação à Docência (PIBID). Demonstrar o paralelo da Filosofia com a realidade circundante e cotidiana dos estudantes é uma maneira eficaz de ressaltar a importância do componente curricular, e é fundamental na ocasião de um primeiro contato. Um(a) professor(a) que não destrua a ilusão da distância entre a atividade filosófica e a vida cotidiana dificilmente conseguirá despertar o interesse e captar a atenção de seus alunos ${ }^{1}$.

Outro critério relevante para a escolha da tragédia em um contexto de introdução à Filosofia é a demonstração da linguagem do logos no texto, já que essa linguagem é a "ponte" entre a tragédia e a filosofia. O gênero trágico esboça dialéticas, argumentos e raciocínios que, embora ainda consideravelmente misturados com a explicação divina mitológica, esboçam os mais claros sinais de fomento à filosofia. Nas argumentações já mencionadas, bem como na argumentação que Clitemnestra tem com o Coro após matar o marido em Agamêmnon, nas motivações de Medeia na tragédia homônima, em toda a atitude investigativa de Édipo, em Édipo Rei, bem como em diversos outros momentos dessas e de diferentes tragédias o logos aparece e se sobressai claramente.

Seja visando uma relação com a realidade atual, seja visando destacar o logos, é bastante possível extrair trechos específicos de diferentes tragédias ao invés de tratar 
uma tragédia específica em sua inteireza. Isso pode até ser considerado preferível, levando-se em consideração que o estilo elevado e a linguagem rebuscada do texto trágico seriam um desafio tanto para a leitura quanto para traçar relações com a contemporaneidade. É verdade que o estilo elevado se apresenta como um empecilho para ler a tragédia com adolescentes, no entanto, a experiência da narrativa não deve ser subestimada. Foi a narrativa, o enredo e, grosso modo, a história contada que manteve o interesse dos adolescentes, mais do que exemplos isolados jamais manteriam. Explicações de palavras vetustas e pausas para interpretação se fizeram necessárias, todavia, a escolha de tratar uma tragédia em sua inteireza, num momento de introdução, foi mais efetiva do que simplesmente recortar exemplos isolados, como veremos adiante.

De acordo com o critério de relação com a atualidade, a tragédia que pareceu mais adequada a uma introdução foi Antígona, de Sófocles. Através dos conflitos principais presentes em Antígona, é possível suscitar relevantes questões filosóficas sobre os mais variados temas como espaço público e espaço privado, validade e origem das leis, conflitos entre leis e costumes, entre leis e religiões, questões de gênero, dentre outras extremamente atuais. As ocupações de moradia urbana, o caso do assassinato de Marielle Franco, a agitação política que o golpe de 2016 e a proximidade das eleições de 2018 geravam, tudo isso poderia ser relacionado. Tomando o cuidado de extrair o conflito da tragédia ao invés de comparar as situações anacronicamente, poder-se-ia, portanto, suscitar os conflitos e relacioná-los com exemplos amplamente conhecidos. No caso do costume e dos valores religiosos que entram em conflito com a lei, há questões que podem ser (e foram) utilizadas como exemplos, como a proibição do uso de véus por meninas islâmicas na França e as práticas religiosas de matriz africana no Brasil. Isso ajuda o professor a ilustrar a contemporaneidade das questões. Além disso, essa obra de Sófocles é bastante encenada e havia a chance de algum aluno já ter assistido no teatro. A relativamente fácil constatação da universalidade e, consequentemente, da atualidade dessa obra de arte são claramente evidentes, clareza que é importante para as aulas dirigidas a um público de Ensino Médio regular.

Por outro lado, de acordo com o critério da demonstração do logos, a obra apropriada seria Édipo Rei, também de Sófocles. Édipo é o herói intelectual per se, aquele que desvendou o enigma da Esfinge e foi, outrossim, a partir de suas capacidades intelectuais que alcançou o poder e o governo de Tebas. O rei investiga (zetein), examina (skopein), questiona (istorien) e utiliza o intelecto do início ao fim do texto, inclusive já utilizando esses termos, que são deveras filosóficos (ROSENFIELD, 2014). A obra inteira consiste em uma busca, em uma investigação "da verdade", que praticamente todos os outros personagens da tragédia tentam esconder. Neste processo, ele despertará terríveis reflexões nos demais tebanos. Sua empreitada terá sucesso e a peripécia e o reconhecimento serão a ruína do herói.

A linguagem filosófica presente em Édipo Rei é verificada a partir de uma análise sutil da tragédia. Édipo encarna muito do logos, tanto que, embora respeite os oráculos, sua investigação está voltada para a busca de uma verdade em termos lógicos e racionais (quem é o criminoso que devo punir para purificar Tebas? Onde ele está?) e a busca vai, catastroficamente, levar a ele mesmo. Alguns dos diálogos de Édipo poderiam ser excelentes exemplos 
caso se optasse por enveredar pela senda da Lógica, o que não foi o caso. Além disso, o processo filosófico que ocorre em Édipo Rei é mais sutil e menos evidente do que o conflito aberto em Antígona. Também é digno de consideração que muito menos paralelos podem ser traçados com a realidade em Édipo Rei do que na outra obra sofocliana. Não há muito terreno evidente em comum entre os acontecimentos do antigo rei de Tebas e o dia-a-dia dos adolescentes do século XXI. Por sua vez, o logos em Antígona é mais fugidio, uma vez que a protagonista está baseada na autoridade de um postulado divino vetusto, e é nessa autoridade que a heroína fundamenta grande parte de seus argumentos. Apesar de ser possível construir argumentos sólidos e válidos nestas condições, o logos se mistura muito com o muthos na argumentação de Antígona, e estamos lidando como uma turma de EM que não têm conhecimentos prévios de Lógica. Por outro lado, é possível traçar uma rica gama de paralelos com a atualidade através dos conflitos presentes em Antígona. Isso aproximaria a turma enormemente da tragédia e, consequentemente, com o auxílio da didática aplicada, da Filosofia.

Para um primeiro contato de um público adolescente, em Introdução à Filosofia, o critério de paralelos com a realidade dos estudantes, através dos conflitos da obra, prevaleceu. As vantagens de Antígona pareceram mais apropriadas para a proposta. É digna de nota a importância de despertar o interesse nos estudantes nesse seu pioneiro caminhar institucional por terreno filosófico. A relação com assuntos atuais estimula a reflexão e ilustra a utilidade e a relevância do conteúdo estudado. Finalmente, além dos critérios envolvidos, a experiência desejada no estágio também pesou nessa decisão. O estágio é um momento de experimentação e aprendizado muito propício para abordagens didáticas arrojadas e pouco convencionais, e era a intenção colocar o suposto didatismo da tragédia à prova empírica.

\section{Método, recepção e narrativa}

Um texto trágico contém uma linguagem culta e uma estrutura que não são aquilo que adolescentes, que passam considerável parte de seu tempo em redes sociais, julgariam atraente. Sendo assim, "o terreno foi preparado" antes de lançar mão da tragédia. As primeiras duas aulas consistiram numa apresentação em Power Point e num texto apresentando aspectos da cultura grega clássica em geral. O Colégio de Aplicação da UFRGS possui dois períodos de Filosofia semanais. As aulas aconteciam toda às quartas-feiras, em dois períodos consecutivos de 45 minutos cada, das 10h40min às 12h10min. Logo, por "uma aula", entende-se esse tempo de dois períodos nesse dia da semana. Essa carga horária foi importante para o sucesso do trabalho realizado no estágio, um tempo menor do que esse prejudicaria a execução. As duas primeiras aulas contiveram também breves referências ao fomento da Filosofia, ilustrando a contribuição que os complexos mitos disseminados em uma língua comum e valorizados por uma cultura oral, ritualística e musicada, bem como a política das diversas pólis e o comércio através do Mar Egeu exerceram no surgimento da arte de pensar.

Os alunos já estavam habituados com a leitura de textos em aula, o professor efetivo já realizava esse procedimento há tempos. Com o texto em mãos, perguntava-se se alguém 
queria ler, e alunos voluntários liam alguns parágrafos por vez. Assim a leitura seguia, só interrompida por observações do estagiário ou por dúvidas dos estudantes. Após, ocorria uma reflexão conjunta sobre o texto. Uma vez que este saudável hábito já estava estabelecido nas aulas de Filosofia da turma, decidimos arriscar o método de leitura dramática e, ao longo da leitura, ir elencando os conflitos filosoficamente relevantes presentes na tragédia. Os alunos encenariam com a voz os heróis da tragédia e o Coro. Para ilustrar para a turma uma aula antes da apresentação de Antígona, levamos um excerto do Canto III da Ilíada no qual Helena discute com Afrodite (v. 390-417). Os estudantes prestaram grande atenção e se divertiram com duas colegas simulando os papéis. A estratégia didática pareceu ter dado o primeiro sinal de que iria funcionar adequadamente.

Houve grande adesão ao método e considerável interesse demonstrado pelos alunos quanto à narrativa. Em geral, a turma se divertiu bastante com a leitura dramática - alguns alunos se destacaram em talento cênico vocal - e as aulas ocorreram de modo mais agradável e produtivo do que o esperado. A narrativa mitológica exerceu um grande fascínio sobre a turma. Eles pareciam muito ansiosos para saber o que aconteceria com a heroína principal. Uma aluna chegou a buscar a obra na íntegra. Por questões de tempo não foi possível ler a tragédia em sua totalidade. Limitamonos ao Prólogo (v. 1-99), ao Segundo Episódio (v. 376-581), ao Terceiro Episódio (v. 626-780) e ao Êxodo (v. 1155-1352). Utilizamos a tradução de Lawrence Flores Pereira.

Ao longo da leitura, o estagiário fazia interrupções para elencar os conflitos que apareciam. Eles eram escritos no quadro, os alunos copiavam e falávamos sobre o conflito antes de prosseguir. Isso foi fundamental, porque a grande contribuição trágica está nos seus conflitos e nas contradições salientadas.

O primeiro conflito que a narrativa apresenta, logo no Prólogo, é entre Antígona e Ismena, uma vez que Ismena se comporta exatamente como seria esperado de uma mulher grega (FOLEY, 2001, pg. 180) como ela mesma diz (v. 61-63): "Pensa nisso também, nós somos só mulheres "Fracas parta enfrentar os homens e sujeitas Ao mando do mais forte". Antígona rejeita pungentemente a atitude da irmã (v. 71-72): "Vamos, segue teu próprio caminho, que eu mesma Sozinha, o enterrarei. É bom morrer assim".

A partir daí, passamos a tratar do primeiro dos conflitos: de gênero. Dialogamos sobre como havia um papel social fortemente determinado, associado ao gênero feminino, que fazia com que Ismena agisse daquela forma e justificasse sua ação, mas que era, ao mesmo tempo, contestado por Antígona. Versamos também sobre como Antígona estava saindo do espaço privado, destinado às mulheres e voltado para família, para intrepidamente entrar no espaço público, palco dos homens e voltado para a política. O papel de gênero feminino é tradicionalmente voltado para a esfera privada, mas o que acontece quando alguma mulher, como Antígona, não está satisfeita com o papel que lhe é atribuído e deseja se mover e agir em desacordo com ele? Era parte da estratégia fazer esse tipo de pergunta com frequência à turma para fomentar pensamentos e reflexões.

Desde o começo, os alunos participaram bastante das respostas a essas questões em sala de aula. As intervenções dos alunos ficaram cada vez mais frequentes e 
mais diretas ao longo das aulas: eles simplesmente davam voz a suas dúvidas, com pouquíssima cerimônia. Aparentemente, o "clima" que a leitura dramática proporcionou, que favorece a desinibição, os fez se sentir mais à vontade para falar livremente. Em alguns casos, houve dificuldade para reestabelecer a norma de dar a palavra a um de cada vez, sendo que muitos falavam ao mesmo tempo e respondiam uns aos outros, no afã de responder aos questionamentos que a análise do conflito presente na obra trágica fomentava. No entanto, muitas das falas dos alunos traziam noções de senso comum, que eram desafiadas respondendo com outra pergunta. Enxergando em retrospectiva, como essas questões despertavam tão claramente o interesse dos estudantes, talvez tivesse sido proveitoso indicar livros sobre filosofia que tratem dessas questões para que eles pudessem investigar e saber mais por si mesmos. "O Segundo Sexo", de Simone de Beauvoir, teria sido a indicação aqui. Obras de Arendt, Thoreau, entre muitas outras, seriam adequadas em outros momentos. Essas indicações, certamente, teriam enriquecido a exposição da Introdução da Filosofia e quiçá lidas por alguns estudantes.

A reação da turma me fez perceber que o objetivo de despertar o interesse foi alcançado, não obstante, o interesse despertado não necessariamente foi o filosófico. Muitos alunos estavam muito mais interessados na narrativa, no que aconteceria com Antígona, o que é bastante apropriado com o modelo de literatura atual ao qual eles estão habituados - o romance. Outros adquiriram um interesse literário na tragédia, o que é promissor, embora também não seja propriamente filosófico. Alguns se interessaram por determinados conflitos abordados, embora fizessem pouco caso de outros. Há aqueles que entenderam e se interessaram tanto pela filosofia quanto pela literatura e, infelizmente, há aqueles que não se interessaram por nada. É preciso reconhecer que, apesar da estratégia didática ter conseguido despertar a atenção da esmagadora maioria da turma, a maior parte do interesse adquirido não foi propriamente filosófico. Apesar disso, a leitura de Antígona os fez mais familiarizados quando nos debruçamos sobre o texto de Platão. A relação de um texto filosófico (a qual, em geral, a maioria os alunos não tende a mostrar inclinação) com a tragédia (a qual a maioria dos alunos, de acordo com a experiência obtida no estágio, tende a mostrar interesse, mesmo que seja pela narrativa) pode fazer o ensino de filosofia mais dinâmico, com uma metodologia menos cansativa e maçante, tirá-lo de moldes que têm pouco apelo a adolescentes. Além disso, a tragédia tem um grande potencial para a interdisciplinaridade, e é possível que um bom projeto que unisse as disciplinas de Filosofia, História, Língua Portuguesa e Literatura poderia se revelar deveras promissor.

O próximo conflito que se fez presente na continuidade da tragédia sofocliana ( $v$. 441-581, argumentação direta entre Creonte e Antígona) foi o conflito entre os costumes (nómos) e as leis do Estado. Quando Antígona enterra o irmão, Polinices, mesmo ciente de Creonte ter proibido o ato e estipulado pena de morte para quem enterrasse o "traidor", o embate se torna inevitável - aliás, foi uma oportunidade para explicar o conceito de dialética. Trata-se do conflito central de Antígona, que coloca a heroína entre a obrigação familiar ancestral de velar os mortos e a obrigação devida às leis da cidade, encarnada na figura 
de Creonte. Esse é o mais famoso conflito abordado por esta tragédia e ele se relaciona facilmente com a contemporaneidade toda a vez que uma lei limita ou restringe um costume há muito estabelecido. O exemplo usado em aula foi o de uma lei francesa que postula que as mulheres muçulmanas estão proibidas de usarem o véu em público naquele país para ilustrar a querela em nossos dias. É uma lei que visa proteger os valores ocidentais seculares, mas se choca contra um costume tradicionalmente estabelecido e, paradoxalmente, diminui a liberdade e a autonomia das mulheres de seguir um costume justamente para proteger a liberdade e a autonomia das mulheres nos países ocidentais. Foi explicado aos estudantes que era filosofia, num sentido latu sensu, pensar e se questionar sobre as leis e a razão de ser de cada lei. Qual é a ideia por trás de cada lei? Deve ser permitido a uma lei barrar um costume? Boa parte dessa aula foi focada na questão sobre o embate costumes $x$ leis, que passou a abarcar outras questões também, como o costume de religiões de matriz africana de sacrificar animais em alguns rituais e como alguns segmentos (por diversos motivos, embora o mais evocado na aula fosse a defesa dos animais) afirmam que tal prática deveria ser proibida. Alguns alunos se lembraram da dificuldade que algumas populações indígenas têm de manter seus costumes, mesmo eles sendo permitidos pela lei. Intrincadas questões sobre até que ponto devemos permitir costumes quando eles se chocam contra os nossos valores, também surgiram. É possível que muitos estudantes tenham se focado em pensar essas questões pela primeira vez nesta aula.

O próximo conflito é mais específico da tragédia. Antígona enterra o irmão para cumprir sua obrigação de velar os mortos, entretanto, esse motivo não é a única motivação de sua ação. Há também um aspecto político em sua ação, porque Antígona é uma epikleros, uma descendente mulher de uma linhagem de reis que não possui mais homens (ROSENFIELD, 2014). A instituição do epiklerato estipula que ela deve se casar com o parente masculino mais próximo, e o filho do casal receberá a linhagem da mãe ao invés da do pai. O parente masculino mais próximo de Antígona é Hemon, último filho vivo de Creonte, o que significa que, se o casamento ocorresse, a linhagem de Creonte desapareceria em virtude da continuação da linhagem dos Labdácidas. Sutilmente para o leitor moderno, embora um tanto evidente para o grego antigo, há um conflito sobre a legitimidade de poder entre a princesa herdeira e o regente. $O$ desafio e a afronta aberta contra Creonte são formas de contestar sua posição ante o povo de Tebas. Aqui é possível extrair questões como: quando e como um poder político é legítimo? Como ele se legitima? Esse conflito, entretanto, foi marginalmente tratado em sala de aula. Foi custoso explicar o epiklerato e, como na tragédia grega o político, o religioso e os aspectos pessoais dos personagens se misturam muito, os alunos tiveram dificuldade de visualizar apropriadamente esse conflito. Além disso, os questionamentos levantados são um tanto mais sutis que os anteriores. Todavia, acredito que possa ser feito apropriadamente com um pouco mais de preparação, cuidado e tempo. É imprescindível uma explanação mais detalhada quando se retira um conflito de uma especificidade complexa da tragédia.

Da tragédia em si, foram estes os conflitos levantados em meio à leitura cativante. Não pareceu produtivo tratar das especificidades sutis de Antígona, porque, 
embora deveras interessantes, elas tendiam a se afastar de uma introdução à filosofia. Ao mesmo tempo, foi notado que ainda se poderia aproveitar muita coisa do rico texto, logo, decidiu-se tratar de algumas interpretações cênicas. O teatro, a exceção de peças preparadas para um público muito específico, faz muitas adaptações do texto original. O grande público não sabe e não há tempo na peça para explicar que Antígona é uma epikleros, dentre outras especificidades culturais da Grécia Antiga. São muito comuns adaptações do texto trágico nas quais, através de uma livre-associação, Creonte é interpretado como uma figura tirânica, associado a ditaduras e desmandos modernos, enquanto Antígona é representada em uma posição associada aos Direitos Humanos, à democracia e a diversas posições de justiça social. Muitas peças de teatro sobre Antígona tratam do texto com adaptações. Como exemplo há a muito famosa adaptação, protagonizada pela atriz Andreia Beltrão, que foi apresentada em 2017 no Teatro São Pedro, em Porto Alegre (PRIKLADNICKI, 2017). As peças atuais, muitas vezes, divergem bastante do texto original.

$A$ adaptação que o teatro faz é anacrônica, adaptada à contemporaneidade. $O$ teatro oferece liberdade artística para tais adaptações e acontecem com muitas outras tragédias além de Antígona. Essas informações foram levadas para a sala de aula e foi constatado que nenhum dos estudantes havia assistido nenhuma peça sobre Antígona, muitos sequer tinha ido ao teatro alguma vez. O Colégio de Aplicação oferece, opcionalmente, a disciplina de Teatro para que eles tenham contato com esse importante elemento de nossa cultura. A existência dessa disciplina foi um alívio, uma vez que, quando alguns dos discentes passaram a questionar sobre questões cênicas, área que não possuo muito conhecimento, pude orientá-los a perguntar para a professora de teatro. Foi cogitada a promoção de uma ação interdisciplinar, no entanto, acabou não acontecendo por incompatibilidade de horários. Houve, contudo, um questionamento sobre a apreciação da arte ao longo do tempo, sua contextualização e a forma como é transmitida e interpretada pelas gerações posteriores, o que foi bastante proveitoso.

A última atividade que trabalhada através de Antígona foi um pequeno texto que comparava as Mães da Praça de Maio com a posição de Antígona e, concomitantemente, os ditadores argentinos de 1966-1973 com a posição de Creonte. Tal como Antígona, aquelas mulheres desejavam enterrar seus entes queridos, como o costume prega, e afirmaram ser seu direito tal ato. Semelhante a Creonte, os militares negam arbitrariamente a elas o seu direito. Fomentei e ajudei a turma a fazer livre-associações semelhantes entre realidades atuais e a querela trágica. Os movimentos de moradia urbana e a vereadora assassinada Marielle Franco foram o consenso da turma. Prossegui pedindo para que eles associassem os conflitos que retiramos do texto original com a situação desses dois exemplos. Marielle Franco abarcou tanto o conflito de gênero quanto o conflito entre costumes e leis, uma mulher que enfrentou uma instituição autoritária e perdeu a vida, tal como Antígona; a questão da moradia urbana, com prédios abandonados sendo ocupados por famílias sem recursos que são despejadas sem nenhuma consideração de uma construção abandonada, e a aspereza disso lhes lembrou Creonte e as leis arbitrárias, mas não se encaixou exatamente em nenhum dos conflitos originais, porque, até onde sabíamos, não 
é exatamente um costume ocupar prédios abandonados. Essa aula foi a de maior sucesso no sentido de participação. Mesmo alguns dos alunos mais tímidos ou indiferentes participaram e prestaram a atenção. Foi necessário, contudo, fazer alertas para se atentar ao conflito, evitando anacronismos, mesmo em um exercício nada rígido de livre-associação.

A leitura da tragédia e as reflexões que dela se sucederam tomaram a maior parte do estágio. O professor supervisor permitiu que assim fosse, e nós concordamos que instigar o pensamento dos jovens através dos conflitos e contradições trágicas era, naquele momento introdutório, mais eficiente e produtivo do que apressar a matéria. Como se tratava de uma abordagem didática experimental, isso foi importante para adquirir resultados. Verificou-se que a tragédia é bastante eficaz em conquistar a atenção dos estudantes e em instigar questionamentos e reflexões, que poderiam ter sido desenvolvidas para muito mais além em alunos que não estivessem tendo uma introdução à filosofia. A tragédia certamente provoca as faculdades intelectuais, contudo, o professor necessita prosseguir trabalhando e desenvolvendo os conceitos, conflitos e desdobramentos presentes na tragédia dos quais tratou para que haja um verdadeiro e significativo aprendizado filosófico.

Além disso, um recurso rico como a poesia trágica abarca tantas e tão diferentes áreas do conhecimento - que deveriam dialogar umas com as outras - que clama por interdisciplinaridade. Aqui se faz oportuno lembrar de evitar o "princípio do presépio":

Pensaremos o currículo como um presépio no qual cada professor
deposita sua oferta de formação e faz assim crescer a árvore-currículo
mediante a agregação de nossa boa vontade? Quando um projeto polí-
tico-pedagógico é concebido assim, ele se transforma em um docu-
mento para alimentar a burocracia, pois uma disciplina não leva em
conta o que acontece na disciplina ao lado; cada um faz o melhor que
pode, mas o resultado final não tem harmonia (ROCHA, 2008, p. 17).

\section{O trágico que conduz à estética}

Uma vez finalizada a leitura do texto sofocliano, adentrou-se os terrenos da filosofia propriamente dita através de trechos do Livro X de A República, de Platão. Foi explicado brevemente o mito da caverna e a teoria das ideias, para contextualizar os alunos, e então prosseguiuse para o conceito de mimesis e para a crítica ferrenha, quase rejeição, que Sócrates faz da arte.

Como era esperado, o estranhamento dos alunos foi maior, uma vez que seu senso comum foi desafiado pelas ideias platônicas. A leitura dramática continuou sendo empregada, contudo, argumentos socráticos são muito diferentes de elocuções trágicas. Foi preciso reler, repetir e explicar diversos trechos do Livro X. Embora estivessem mais silenciosos e desafiados intelectualmente, os alunos não estavam menos interessados - e possivelmente estariam caso um texto de Platão fosse aplicado desde o início, sem usar um recurso didático atraente.

Conhecedores da poesia trágica, eles foram capazes de acompanhar um diálogo que versa deveras sobre a poesia grega já entendendo um tanto do que essa poesia tratava. Ler Antígona facilitou o entendimento da compreensão do Livro X de A República. 
O estágio acabou com esse conteúdo ao aplicar um trabalho e uma prova, todavia, o plano de aulas poderia se estender para muito além nas mãos de um professor com um ano letivo inteiro pela frente. Tendo a tragédia como obra de arte exemplar, seria possível traçar um módulo de Estética que continuasse a partir da Poética, de Aristóteles, passando pelas ideias de Lessing e seu conceito de Mitleid, Hume e seu padrão do gosto, o juízo estético kantiano, a dialética de Hegel e o emblemático papel que o filósofo concede à Antígona, Nietzsche e seu O Nascimento da Tragédia e chegando a nossos dias com Arthur Danto e sua classificação dos tipos de texto existentes, bem como a própria definição de arte. Esse plano de aulas foi idealizado a partir da experiência de estágio. O gênero trágico é muito rico, diversos planos de aula podem começar a partir dele.

\section{Considerações finais}

O gênero trágico precisa ter seu pó espanado das estantes dos eruditos e dos acadêmicos e ser disseminado como obra de arte exemplar que é. Há enormes possibilidades didáticas para tais textos. A riqueza da tragédia pode e deve ser usada em favor da educação básica. Os conflitos presentes na obra, uma vez compreendidos, eliminam deveras a distância que há entre a tragédia e a atualidade, embora uma compreensão completa da sutileza trágica demande considerável percepção e estudo. Mesmo a livre-associação, com o devido cuidado para que sejam identificados os anacronismos, pode se mostrar proveitosa. No chão da escola, a tragédia ateniense também é capaz de ser o fio condutor que une uma disciplina às outras e o estudante com a vontade de aprender, contribuindo para desenferrujar a contraproducente educação mecânica e penosa que não raro sufoca a escola de nossos tempos e isola as disciplinas e os professores uns dos outros. Finalmente, narrativas como essas são capazes de despertar o interesse dos estudantes, um fator fundamental que deve ser levado em conta na aplicação de qualquer didática.

\section{Referências:}

ARISTÓTELES. Poética. Brasil: Abril Cultural, 1984.

FOLEY, H. P. Female Acts in Greek Tragedy. New Jersey: Princeton University Press, 2001.

HOMERO. Ilíada. Tradução de Frederico Lourenço. São Paulo: Companhia das Letra, 2018.

PLATÃO. A República. São Paulo: Difusão Europeia do Livro, 1965.

PRIKLADNICKI, Fábio. Andrea Beltrão estrela o solo "Antígona" no Theatro São Pedro, em Porto Alegre. Gaúcha ZH, Porto Alegre, set., 2017. Disponível em: https://gauchazh.clicrbs. com.br/cultura-e-lazer/espetaculos/noticia/2017/09/andrea-beltrao-estrela-o-solo-antigona-no-theatro-sao-pedro-em-porto-alegre-9907701.html. Acesso em fev., 2019. 
ROCHA, P. R. Ensino de Filosofia e Currículo. Petrópolis, Rio de Janeiro: Vozes, 2008.

ROSENFIELD, K.H. Representações da inteligência feminina na Grécia Clássica: Clitemnestra, Jocasta e Antígona. Revista Linguagem \& Ensino, Pelotas, v. 17. n.1, p. 187-214, jan./abril, 2014.

\section{Notas}

1 É verdade que há teorias e questões metafísicas e/ou muito específicas e sofisticadas (como o Idealismo Transcendental, o Solipsismo, entre outras) que reforçam a ideia trivial de que a Filosofia é uma atividade muito específica e muito distante da realidade prática dos alunos. Naturalmente, essas teorias e questões não são apropriadas quando o objetivo é traçar um paralelo com a realidade cotidiana dos estudantes para que, assim, eles percebam a importância da atividade filosófica. Não é minha intenção adentrar a discussão complexa sobre os conteúdos de Filosofia no Ensino Médio, contudo, caso alguém queira abordar estas questões e teorias, não parece razoável que o faça nas aulas de Introdução à Filosofia. São temas para mais adiante no decurso do EM.

\section{Correspondência}

Tiago Irigary de Bem - Av. Bento Gonçalves, 9500 - Agronomia, CEP: 91509-900, Porto Alegre, Rio Grande do Sul, Brasil.

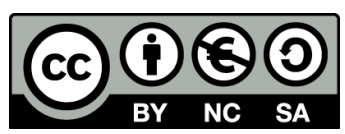

This work is licensed under a Creative Commons Attribution-NonCommercial 4.0 International (CC BY-NC 4.0) 